\title{
Contribuições para a divulgação da pesquisa em educação produzida no Brasil na contemporaneidade
}

Sabemos que os problemas e impasses da educação brasileira contemporânea não preocupam apenas os educadores. A dimensão e gravidade da quase crônica crise educacional que vivemos, bem como os desdobramentos que ela provoca em diversos setores da sociedade, fizeram que ela se tornasse um grande problema nacional, sobre o qual muitos opinam: desde aqueles que estão direta ou indiretamente envolvidos com a administração pública, passando por empresários e jornalistas, até profissionais e pesquisadores de outros campos, muitos associados a algum tipo de organização do chamado terceiro setor.

0 desenvolvimento da pesquisa em Educação no Brasil, por sua vez, sobretudo nos últimos anos, com a expansão dos programas de pós-graduação, tem trazido contribuições significativas para o enriquecimento da compreensão dos processos educativos, particularmente escolares (aquilo que alguns autores chamam de forma escolar de socialização ou gramática da escola contemporânea). Nesse contexto, as revistas acadêmicas especializadas em educação, como a Revista EDUCAÇÃO E PESQUISA e alguns outros notáveis periódicos, representam veículos imprescindíveis, capazes de divulgar os resultados de pesquisas e estudos sistemáticos sobre as questões educacionais, fundamentais para embasar determinadas posturas e concepções e, conseqüentemente, para elevar o nível do debate realizado na atualidade.

0 conjunto de textos selecionados neste número exemplifica como as instituições, práticas e relações sociais estabelecidas no âmbito educacional e escolar podem ser vistas e analisadas a partir de diferentes enfoques e com diferentes métodos. Alguns pesquisadores adotam uma metodologia qualitativa, outros recorrem à perspectiva quantitativa; alguns inovam na utilização de métodos, ousando criar novos procedimentos investigativos; outros são mais conservadores, mas conforme o leitor poderá constatar, todos os textos se fundamentam em conhecimento acumulado e obedecem a exigências de rigor, objetividade e coerência no tratamento do material empírico ou na construção das categorias analíticas e das interpretações, conforme comentaremos a seguir.

0 texto Reformas educativas, viagem e comparação no Brasil oitocentista: o caso de Uchoa Cavalcati (1879), de Alessandra Frota Martinez de Shueler e José Gonçalves Gondra, aborda assunto importante da história da educação num período ainda pouco estudado: a situação das escolas públicas na sociedade brasileira no final do século XIX, no final do Império. Os autores examinam a viagem de Uchoa Cavalcanti (Inspetor de Instrução Pública da Província de Pernambuco) à Corte e às Províncias do Rio de Janeiro e São Paulo em 1879, por meio do relatório oficial dessa viagem (intitulado: Instrução Pública - estudo sobre o sistema de ensino primário e organização pedagógica das escolas da Corte, Rio de Janeiro e Pernambuco). De acordo com os pesquisadores, a leitura do documento objetivou "observar as condições gerais da viagem e da narrativa construída pelo inspetor como estratégia para discutir as representações que produz, com especial destaque às relativas à Corte e à Província do Rio de Janeiro. Nesse sentido, analisamos as fontes manejadas pelo autor, articulando-as com o que é produzido pelo seu testemunho e experiência pessoal. Assim, a abordagem privilegia a discussão de questões como: a difusão e a circulação 
interprovincial de idéias e modelos pedagógicos; as apropriações e as representações construídas a respeito das escolas visitadas, de seus professores e das iniciativas pedagógicas observadas; e ainda os efeitos comparativos que produz em relação à sua própria experiência como inspetor de instrução pública em Pernambuco. Importante fonte documental, o relatório traz informações sobre a situação das escolas na época como, por exemplo, o modo como o sistema educacional e o espaço escolar era organizado, as práticas pedagógicas adotadas pelos professores e os aspectos do cotidiano escolar de algumas instituições. Ao discutir a maneira como as primeiras classes na forma de ensino simultâneo eram estruturadas e, principalmente, ao apontar a pluralidade de formas de escola que vigoravam no Brasil daquele período, o estudo oferece elementos instigantes para renovar algumas teses já consagradas no campo da historiografia educacional, como a de que a escola brasileira foi edificada a partir de um centro (do Rio de Janeiro, na condição de Corte), capaz de emanar um único modelo copiado pelo restante do Brasil. Conforme avaliam os autores: "No conjunto, o inspetor procura levar a bom termo seu objetivo de contrastar a ciência que possui com aquilo que observa in loco. Nesse exercicio, o inspetor constrói uma narrativa que ajuda a problematizar teses recorrentes na historiografia (geral e da educação) que estabelecem a Corte e a província do Rio de Janeiro como modelos para a nação. Com base nesse relatório, a comparação intranacional se põe como exigência para fertilizar reflexões relativas à variedade das formas escolares em funcionamento no século $\mathrm{XIX}$, ajudando a matizar a tese de um poder vertical que teria organizado uma única forma para o Brasil e para suas escolas".

O segundo texto publicado neste número, Articulação entre primário e secundário na era Vargas: crítica do papel do estado, elaborado por Maria Angélica Pedra Minhoto, também apresenta os resultados de uma pesquisa no campo da história da escolarização no Brasil. Baseando-se no exame de dados empíricos, o artigo traz contribuições para o exame do papel do Estado (entendido como organização burocrática em processo de modernização e com vistas à racionalidade da administração pública) como instância reguladora do sistema educacional. Nas palavras da autora: "0 texto tem como objetivo caracterizar o peso seletivo do exame de admissão ao ginásio, nas décadas de 1930 e 1940, tendo em vista a política pública do governo Vargas para o ensino secundário. Para tanto, verificou-se o padrão de recrutamento estabelecido pelo exame, bem como as relações entre os estímulos presentes nas determinações legais para a organização do exame e as respostas dos estabelecimentos de ensino a tais prescrições".

A pesquisa foi realizada em arquivos de cinco diferentes instituições de ensino, que funcionavam no período estudado, localizadas na cidade de São Paulo, a saber: uma instituição pública (mista), a única em funcionamento na cidade no período examinado, e quatro instituições privadas: duas católicas (sendo que duas eram destinadas exclusivamente ao público masculino e uma ao público feminino), uma protestante (mista) e uma laica (mista). As instituições examinadas permanecem abertas até hoje. De acordo com o que já foi apontado por outras investigações, a pesquisa demonstrou que os exames de admissão apenas confirmam um recrutamento feito anteriormente baseado no grupo social a que pertence o estudante: "Os resultados obtidos indicam que o exame legitimou um padrão específico de recrutamento de alunos e camuflou a existência de barreiras institucionais no ensino elementar. Ademais, as estratégias desenvolvidas pelas instituições privadas para contornar sistematicamente a regulamentação jurídica do exame permitiram entrever limites ao papel repressivo e interventor do Estado da época”. 
O texto Educação e liberdade em Hannah Arendt, de Vanessa Sievers de Almeida, por sua vez, explora um tema sempre pertinente para a educação contemporânea: as complexas relações e tênues fronteiras entre educação/sujeição e liberdade. 0 artigo é fruto de pesquisa teórica, elaborada a partir da incursão ao pensamento da filósofa Hannah Arendt. Embora trabalhe com textos bastante conhecidos de Arendt, o artigo propõe uma reflexão original sobre as difíceis relações entre singularidade e pluralidade, e entre liberdade e imprevisibilidade da ação humana. A pesquisadora pretende mostrar que há, na abordagem arendtiana, uma relação essencial entre educação e liberdade, embora não estabelecida de forma direta. 0 texto apresenta também uma discussão sobre os possíveis desdobramentos dessa interface para uma reflexão sobre o sentido da educação: "0 presente artigo investiga, numa perspectiva filosófica, a relação entre os conceitos de educação e liberdade nos escritos de Hannah Arendt. Sustenta-se que, embora a autora não aponte para isso, existe em seu pensamento uma relação essencial entre esses conceitos. A interface principal é a natalidade, o fato de seres novos nascerem para um mundo já constituído. Dessa condição existencial decorre, por um lado, a potencial liberdade do ser humano, a capacidade de iniciar algo inesperado e, por outro, a necessidade de acolher os novos num espaço comum que é mais velho do que eles. A tarefa da educação é contribuir para que os 'recém-chegados' se apropriem desse mundo que lhes é legado, possibilitando assim que futuramente assumam a responsabilidade por ele. Isso, no entanto, implica na necessidade de arrumar esse lugar, que está 'fora dos eixos'. A ação educativa nesse sentido, porém, pode ser apenas indireta: sendo que todo ser humano nasce como alguém singular, diferente de qualquer outro, cada um é uma novidade para o mundo e, por isso, é, a princípio, capaz de transformá-lo, começando algo novo".

O texto Geografia e Cartografia escolar: o que sabem e como ensinam professoras das séries iniciais do Ensino Fundamental, de autoria de Adriano Rodrigo Oliveira, insere-se em uma vertente de pesquisa sobre formação de professores que tem recebido maior atenção da comunidade acadêmica brasileira especialmente na última década: a dos saberes docentes. Destacando a necessidade de seu reconhecimento e de sua valorização, vários trabalhos de pesquisa têm buscado desenvolver formas de aproximar-se da realidade das escolas e das práticas de professores, almejando construir conhecimentos significativos que auxiliem a construção de uma nova concepção de formação e desenvolvimento profissional docente. É na esteira desse processo, ainda em construção, que se inscreve a investigação de Oliveira sobre a geografia e a cartografia ensinada nas escolas, desenvolvida com duas professoras de $4^{\text {a }}$ série do Ensino Fundamental da rede estadual do município de Limeira, interior do estado de São Paulo.

0 autor buscou aproximar-se, identificar e analisar as práticas das professoras, bem como as dificuldades por elas enfrentadas no uso de mapas do atlas municipal escolar de Limeira. Conclui que "os saberes das professoras acerca de conhecimentos cartográficos têm sua origem na experiência cotidiana do trabalho docente; envolvem saberes advindos principalmente do contato e da experiência com outras professoras; das imagens e memórias de quando eram alunas; e do uso de livros didáticos. Verificamos com os sujeitos dessa investigação que o atlas gera no contexto escolar processos de ensino e aprendizagem motivadores no sentido de tratar de problemáticas locais vivenciadas tanto pelas professoras como pelos alunos”.

Embora com objetos, preocupações e perspectivas teóricas distintas, os dois textos subseqüentes fornecem aportes férteis e instigantes para a pesquisa em Educação a partir do relato de duas pesquisas na área de Educação Matemática. 
Em Um ensaio sobre as concepções de professores de Matemática: possibilidades metodológicas e um exercício de pesquisa, Antonio Vicente Marafioti Garnica toma como objeto de estudo as concepções de professores de Matemática. Valendo-se de uma linguagem dialógica e instigante, Garnica captura a atenção do leitor ao reconstruir as questões subjacentes a sua busca por um método "que nos permita ter as 'concepções' como tema central num processo de investigação”. 0 objeto ‘concepção' é de fato construído em diálogo crítico e profícuo com a produção acadêmica na área, relacionando-o ao conceito de ação. Posiciona-se da seguinte maneira: “[...] diríamos que as frases que repetimos sobre nossas concepções podem deixar nubladas essas nossas concepções. Ainda assim, a ação de dizer tais frases, a enunciação - ela própria - e nosso hábito de reproduzi-las incessante e intensivamente, dão-nos indicativos - insistimos - do nosso desejo de inscrição numa certa comunidade, do nosso desejo de sermos reconhecidos como membros de um grupo que constituímos e mantemos com nossos discursos". Tributário do pragmatismo de Peirce, o autor apresenta uma discussão sobre as possibilidades de se construir um conjunto de parâmetros metodológicos - chamado de "método indireto" - que permita tomar o estudo das 'concepções' em sua complexidade e contradições. 0 autor apresenta o que denomina como "um exercício" desse método que se vale, dentre outros recursos teórico-metodológico, de uma abordagem indireta ao sujeito. Para "auscultar, por exemplo, as concepções dos professores de Matemática acerca da Matemática, interpelando-os não sobre essas concepções, mas sobre suas práticas”. Tem-se aqui uma contribuição original para pesquisadores em busca de formas combinadas de produção de dados na pesquisa empírica em Educação.

Também no campo da Educação Matemática, o relato de uma segunda pesquisa é publicada nesse número. Trata-se de artigo intitulado Mulheres, homens e matemática: uma leitura a partir dos dados do indicativo nacional de alfabetismo funcional, em que Maria Celeste Reis Fernandes de Souza e Maria da Conceição Ferreira Reis Fonseca se debruçam sobre uma questão com contornos contemporâneos, apesar de atravessar a história da humanidade: as diferenças entre homens e mulheres. Mais especificamente, as autoras abordam questão ainda pouco estudada pela pesquisa educacional brasileira envolvendo as complexas articulações entre relações de gênero e conhecimento matemático. Tomam como fonte os resultados do $4^{\circ}$ Indicador Nacional de Alfabetismo Funcional (INAF/2004), fruto de pesquisa realizada em parceria entre o Instituto Paulo Montenegro e a ONG Ação Educativa. As pesquisas INAF propõem-se a construir perfis da população brasileira jovem e adulta quanto a suas condições de inserção em sociedades pautadas por critérios e práticas da cultura escrita. Comparando-se os resultados do ano de 2004 com os obtidos na edição anterior (2002), as autoras registram a permanência da diferença de desempenhos entre homens e mulheres no tocante às habilidades matemáticas nas tarefas cotidianas, favorável aos homens. A partir de uma releitura desses resultados, as autoras pretendem "imprimir um olhar sobre essas diferenças, expressas nos resultados apresentados pelas mulheres e pelos homens, propondo que o discurso sobre essas diferenças produz verdades sobre mulheres e homens, gerando, nas práticas sociais, situações de desigualdade”.

Embasadas numa perspectiva foucaultiana, remetem à necessidade de entender "esses resultados como articulados a um campo discursivo, marcado pela racionalidade matemática de matriz cartesiana." Destacam ainda a importância de se problematizar e desconstruir 
discursos veiculados em diversos espaços, inclusive no âmbito da escola, que acabam por naturalizar as diferenças no desempenho matemático entre homens e mulheres.

No Brasil, estudos sobre o chamado "efeito escola" são ainda recentes. 0 interesse da comunidade acadêmica em produzir estudos dessa natureza tem sido impulsionado com a disseminação de práticas avaliativas de sistemas de ensino, em nível nacional, como, por exemplo, o Sistema de Avaliação da Educação Básica (SAEB) sob responsabilidade do Instituto Nacional de Pesquisas Educacionais (INEP). Em diálogo crítico com essas políticas de avaliação de sistemas de ensino, Maria Teresa Gonzaga Alves e José Francisco Soares apresentam, em $O$ efeito das escolas no aprendizado dos alunos: um estudo com dados longitudinais no ensino fundamental, resultados de um estudo longitudinal realizado com 1194 alunos do segundo ciclo do Ensino Fundamental. Esses alunos, oriundos de sete escolas públicas situadas em Belo Horizonte, com perfil socioeconômico e localização semelhantes, foram submetidos à aplicação de testes de matemática e língua portuguesa em três ocasiões. Foram também convidados a responder a um questionário com a finalidade de levantar informações sobre características demográficas e socioeconômicas da população da amostra.

No que se refere à metodologia adotada no estudo, os autores concluem que "o trabalho mostrou várias descobertas relevantes e trouxe contribuições metodológicas para o uso de modelos multiníveis para a análise de dados longitudinais, o que permitiu incorporar a dinâmica do processo de aprendizagem nos modelos de análise. A apresentação dessa nova abordagem pode significar um desafio para as políticas públicas de avaliação de sistemas de ensino ao revelar que resultados pontuais medidos por meio de levantamentos transversais não constituem a melhor evidência para a avaliação das escolas em termos do aprendizado de seus alunos. Para isso, a experiência deste estudo mostra que, além da coleta de dados longitudinais, idealmente, deve-se realizar pelo menos duas ondas de coleta de dados em cada ano letivo, considerando as mudanças significativas na base de alunos de um ano para outro que se observa no sistema escolar".

As contribuições da teoria psicanalítica para pensar o campo da educação escolar, especificamente a tarefa educativa em seus aspectos inconscientes, não é tema novo na literatura acadêmica, mas é abordado com originalidade no artigo Sala de aula e teceturas subjetivas de Vera Lúcia Blum.

Ao tomar a relação professor-aluno como objeto de estudo, a autora ocupa-se das demandas organizativas da sala de aula - ideais de ordem e harmonia, nas palavras de Blum - em suas relações com as demandas e forças do inconsciente. 0 percurso reflexivo da autora é fundamentado em conceitos da psicodinâmica grupal com uso de noções psicanalíticas já conhecidas do meio educacional como grupo de suposto básico, identificação projetiva; introduz, ainda, outros conceitos ainda pouco explorados, pois "procura-se pensar o espaço intersubjetivo segundo uma lógica que considere a criação de uma terceiridade no ensinar e aprender. Introduz-se a noção de 'terceira voz' (Ogden) para indicar a criação e recriação do outro intersubjetivo, que faz da atividade docente uma experiência geradora de turbulência emocional com efeitos diversos nas constituições subjetivas. 0 enrijecimento identitário, com o concomitante desdém e intolerância à diferença, pode ser uma forma de reagir àquilo que escapa ao controle e à previsibilidade e que enfraquece desse modo os movimentos transformacionais implicados no processo de aprendizagem". 
Em Exercício docente na escola: relações sociais, hierarquias e espaço escolar, Marieta Gouvêa de Oliveira Penna discute o exercício docente a partir de uma análise relacional entre condições de trabalho e posição social. Trata-se de parte das análises de uma pesquisa desenvolvida pela autora em seu doutoramento no Programa de Estudos Pós-Graduados em Educação da Pontifícia Universidade Católica de São Paulo.

0 texto analisa as condições de trabalho dos professores quanto aos aspectos relacionados ao espaço escolar, às suas dificuldades no trato com os alunos, às possibilidades de exercicio autônomo na condução das tarefas cotidianas e, finalmente, às relações hierárquicas na escola. Tendo como "objetivo evidenciar aspectos das condições objetivas de trabalho dos professores, que constituem e são constituídas pela posição por eles ocupada no espaço das relações sociais, numa relação de múltiplas determinações. A posição ocupada pelo professor no espaço das relações sociais e as condições objetivas em que o desempenho dessa função se desenvolve se expressam no habitus relacionado ao exercício dessa função".

0 referencial teórico ancora-se em conceitos oriundos da abordagem bourdieniana, mais especificamente nas noções de habitus, capital cultural e distinção; de Guimeno Sacristán, toma emprestado o conceito de prática docente, entendendo-a, portanto, como "cultura objetivada na forma de um legado imposto aos sujeitos, expressando-se como sabedoria compartilhada, ações a serem executadas ou mesmo estilos docentes". A pesquisa empírica foi realizada por meio de entrevistas semi-estruturadas com dez professoras do ciclo 1 do Ensino Fundamental de uma escola pública. Coincidente com os estudos anteriores, a autora depara-se com uma realidade objetiva de desprestígio da profissão docente. "No entanto, mesmo sendo função desvalorizada socialmente e em face às difíceis condições objetivas a que estão submetidos como, por exemplo, a falta de autonomia para a condução de seu trabalho, para os professores exercer docência significa valor, não só em razão de ganhos econômicos advindos com o salário recebido, mas especialmente em decorrência do capital simbólico que capitalizam nas relações de distinção estabelecidas na escola. Além disso, exercer a docência significou elevação concreta do capital cultural dos professores, ao se levar em consideração suas famílias de origem".

Neste número, publicamos a tradução do texto Parcerias público-privadas, empresas digitais e a produção de um espaço educacional neoliberal em escala européia (título original: "PublicPrivate Partnerships, Digital Firms and the Production of a Neo-Liberal Education Space at the European Scale") de Susan L. Robertson, do Centre for Globalisation, Education and Societies, da University of Bristol, UK. 0 artigo traz insumos significativos para o estudo das políticas educacionais contemporâneas a partir do exame das medidas que vem sendo tomadas no âmbito na União Européia. 0 texto se organiza da seguinte maneira: "se inicia com um esboço dos principais argumentos teóricos sobre a produção de escala e a reorganização do espaço público para, em seguida, tratar de um estudo de caso: uma análise de discurso aplicada ao relatório do Encontro de Cúpula Europeu sobre elearning (aprendizagem por meios eletrônicos) (European eLearning Summit), promovido pelo setor privado em 2001, na Bélgica. Apresenta-se ainda como tal iniciativa está ligada a um projeto europeu de maior amplitude - a criação de um Espaço Educacional Europeu, estrategicamente desenvolvido pela Comissão Européia - e argumenta-se que esse projeto pode ser visto como um processo de criação de territórios em âmbito europeu. Nas seções finais 
desse artigo, examina-se como os interesses do setor privado se inserem no projeto europeu de Educação, por meio do favorecimento de relações público-privadas como um mecanismo para o desenvolvimento. Por fim, conclui-se que esse novo mecanismo de governança constrói um conjunto de relações sociais em nível europeu que privilegia interesses particulares; os interesses de empresas digitais transnacionais e o tipo de conhecimento que elas promovem". Embora analise um problema no contexto europeu, a leitura do artigo nos permite constatar que nossos problemas educacionais não são muito diferentes daqueles que mobilizam os pesquisadores de outros países.

Finalmente, aproveitamos para agradecer, mais uma vez, a inestimável colaboração dos pareceristas dos artigos publicados neste número. Sem o espírito crítico e olhar atento de cada parecer elaborado, este fascículo não teria alcançado o resultado satisfatório que alcançou.

Denise Trento Rebello de Souza e Teresa Cristina Rego 